\title{
XANTHOMA OF ULNA
}

Vishwanath Yaligod ${ }^{1}$, Siddarth Mahesh², Girish H Rudrappa ${ }^{3}$, Lokesh Choudhary ${ }^{4}$

\section{HOW TO CITE THIS ARTICLE:}

Vishwanath Yaligod, Siddarth Mahesh, Girish H Rudrappa, Lokesh Choudhary. "Xanthoma of ulna". Journal of Evolution of Medical and Dental Sciences 2013; Vol2, Issue 35, September 2; Page: 6691-6695.

ABSTRACT: Skeletal xanthomas are extremely rare benign disorders with features mimicking bone tumours and their definitive diagnosis is very difficult. Patients diagnosed with primary xanthoma should be followed up regularly as they may develop dyslipidemia later. Xanthomatous degeneration occurring in other bony lesions should be differentiated with xanthomas by studying the whole specimen microscopically. A 45 year old lady presented to us with xanthoma of ulna who was a known diabetic and hypothyroid on treatment. Ours is the second case of ulnar xanthoma reported so far in the literature.

KEY WORDS: Xanthoma, ulna, benign.

INTRODUCTION: Xanthoma the word derived from the Greek "Xanthos" meaning yellow. They are benign lesions developing due to abnormal deposition of cholesterol. They are commonly found in skin around the eyes (Xanthelasma), over the joints (Xanthoma tuberosum), in the tendons of the extremities (Xanthoma tendinosum). Xanthomas of skeleton are rare disorders ${ }^{1}$ but are important due to their presenting features mimicking bone tumors and definitive diagnosis before the surgery is very difficult ${ }^{2}$.

CASE REPORT: A lady aged 45 years presented with history of swelling in the right forearm since 6 years. The swelling was not associated with pain initially, since 2 years some dull aching pain on activity. She is a known case of diabetes and hypothyroidism since three years, on regular treatment. On examination $2 \times 2 \mathrm{~cm}$ bony swelling noted in the mid ulna. The radiography showed (Fig.1) osteolytic lesion in the mid shaft of ulna - expansile in nature with sclerotic margin, suggestive of benign nature of the lesion. Excisional biopsy and curettage was planned. Per-operatively on making a cortical window, the cavity was found filled with yellowish soft material (Fig. 2) which was curetted out. The cavity bed appeared like a sieve (fig.3) due to multiple perforations. The cavity packed with bone graft taken from the proximal ulna. On histopathological examination, sheets of lipid laden foam cells with variable background of other cells and fibrosis was noted (fig.4). There were cholesterol clefts with giant cells around them (fig.5) in certain areas. These features were suggestive of xanthoma. Retrospectively we analysed the lipid profile of the patient which was found to be normal, however, we could find a xanthelasma lesion over left upper eyelid (Fig 6). Four months post operatively the bone graft incorporated well and no sign of recurrence and the patient still needs to be followed up.

DISCUSSION: Skeletal xanthomas are rare, non neoplastic disorders presenting diagnostic dilemma to orthopaedic surgeons as their clinical and radiological features present like bone tumors. The possible proposed pathogenesis ${ }^{3}$ of xanthomas may be due to leakage of the lipids and cholesterols at the site of the lesion which attract macrophages. These macrophages engulf the lipids and cholesterols and look like typical foamy cells on histopathology. Minor trauma ${ }^{4}$ or pre existing bony 
lesion may be triggering factors to the development of these lesions. When they occur in the pre existing bony lesion like simple bone cyst, aneurismal bone cyst, fibrous dysplasia and some malignant tumours they are called as xanthomatous variant ${ }^{5}$. Such Xanthomatous changes in the pre-existing bony lesions usually occur only in certain areas of the whole lesion suggesting degenerative nature. Kapukaya et al. ${ }^{5}$ suggested to examine the whole biopsy material microscopically in order to avoid erroneous diagnosis on histopathology.

Most cases of skeletal xanthomas are associated with lipid metabolism disorders, hyperlipidaemias, hypothyroidism, diabetes mellitus and other endocrine disorders, and are called as secondary xanthoma 5 . So a patient with skeletal xanthoma should be thoroughly evaluated to rule out underlying disease states 6 .When skeletal xanthomas occur without any underlying cause and the patient having normal lipid levels they are called as primary xanthoma ${ }^{5}$. Since skeletal xanthoma may be the first sign of dyslipidaemia ${ }^{1}$ and dyslipidemia may develop years after the appearance of xanthoma, we should use the term primary xanthoma very carefully.

Skeletal xanthomas are solitary lesions, rarely multiple ${ }^{2,7}$. They are common in males with ratio of 2:1 in a larger series of Xanthomas of bone reported ${ }^{7}$. They are common in flat and cancellous bones and are rare in cortical bone. Very rarely they break the cortex and extend into the surrounding soft tissues ${ }^{2,5}, 8$. They usually present between third and fifth decade of life ${ }^{9}$. The size of the lesion is usually 2-5 cms. Frequently the presenting symptom is pain and sometimes discovered incidentally. The lesion can present as a pathological fracture also ${ }^{2}$.

On plain radiograph the lesion appears as a well defined osteolytic expansile lesion with small areas of surrounding reactive bone or a distinct sclerotic margin. In these expansile lesions, often there is cortical disruption. Such an aggressive appearance raises the suspicion of malignant bone tumours and may lead to many unnecessary investigations which can have an impact on the patient both emotionally and financially. During surgical excision, the cavity is usually found filled with soft yellowish mass, with wall of the cavity showing sieve like perforation ${ }^{1}$.

Microscopically the lesion is essentially benign in nature with sheets of foamy macrophages (histiocytes) interspersed in to the trabeculae embedded in a variable background of cells and fibrosis. The composition of foam cells relative to fibrous stroma varies in case to case. There are cholesterol clefts and giant cells around them in focal areas. Most often the diagnosis is done after the surgery and biopsy and in most of the published cases the lipid profile was done after the establishment of diagnosis of skeletal xanthomas. Usually the xanthomas are associated with Type II \& III hyper lipoproteinaemias, diabetes mellitus, hypothyroidism etc. which need to be diagnosed and treated appropriately. The prognosis is good even after partial excision ${ }^{10}$. Since surgical curettage of the lesion is curative, the skeletal xanthoma should be kept in mind if we come across the typical per operative findings to avoid more aggressive treatment than necessary.

CONCLUSION: Skeletal xanthomas are very rare lytic expansive lesion of bone occasionally showing aggressive radiological features which necessitates ruling out the malignant bone tumours. The xanthomatous degeneration (variant xanthoma) occurring in other bone tumours need to evaluated carefully in whole of the specimen to avoid erroneous diagnosis of primary xanthoma. Even the cases of primary xanthoma, may subsequently develop dyslipidemia later. Hence recommended to follow them with regular lipid and thyroid profile tests. The present case is the second case xanthoma of shaft of ulna published in the literature. 


\section{BIBLIOGRAPHY:}

1. D. Dallari, et al., "Xanthoma of Bone: First Sign of Hyperlipidemia Type IIB: A Case Report," Clinical Orthopaedics and Related Research, Vol. 410, 2003, pp. 274- 277. doi:10.1097/01.blo.0000063790.32430.10

2. Vallabhaneni Kalyan Chakravarthi, E. Aruna, Damera Naveen Chandra Rao, Diddi Ranga Rao. Bilateral Tibial Xanthoma in a Normolipidemic Patient-Report of a Rare Case with Review of Literature. International journal of clinical medicine, 2012, 3,234-237.

3. FM de Moraes Ramos-Perez, JM de Pádua, YTC Silva-Sousa, OP de Almeida, and DE da Cruz Perez Primary xanthoma of the mandible, Dentomaxillofac Radiol. 2011 September; 40(6): 393-396. doi: 10.1259/dmfr/51850495

4. Bonhomme GR, Loevner LA, Yen DM, Deems DA, Bigelow DC, Mirza N. Extensive intracranial xanthoma associated with type II hyperlipidemia. AJNR Am J Neuroradiol 2000; 21:353-355.

5. Ahmet Kapukaya, Husseyin Arslan, Emin Ozkul, Bulent Mizrak. Primary xanthofibroma in the calcaneus: a case report. Acta Orthop Traumatol Turc, 2011:45(3): 203- 207.

6. E. T. Elwood, et al., "Isolated Xanthoma of the Frontal Bone," Journal of Craniofacial Surgery, Vol. 16, No. 3, 2005, pp. 391-394. doi:10.1097/01.scs.0000171963.93992.23

7. Bertoni F, Unni KK, McLeod RA, Sim FH. Xanthoma of bone. Am J Clin Pathol 1988; 90:377384.

8. J. Kris, F. Edward and L. Kristy, "Weber, Xanthoma of Bone: A Report of Three Cases and Review of the Literature," The Iowa Orthopaedic Journal, Vol. 28, 2008, pp. 58-64.

9. Boisgard S, Bringer O, Aufauvre B, Joudet T, Kemeny JL, Michel JL, et al. Intraosseous xanthoma without lipid disorders. Case-report and literature review. Joint Bone Spine 2000; 67:71-74.

10. Hasnae Guerrouj, Ayat Mouaden, Nouzha BenRais. Xanthoma of Bone: A case report. Case reports in endocrinology, Vol 2012, Article ID 986952, 3 pages, doi:10.1155/2012/986952.

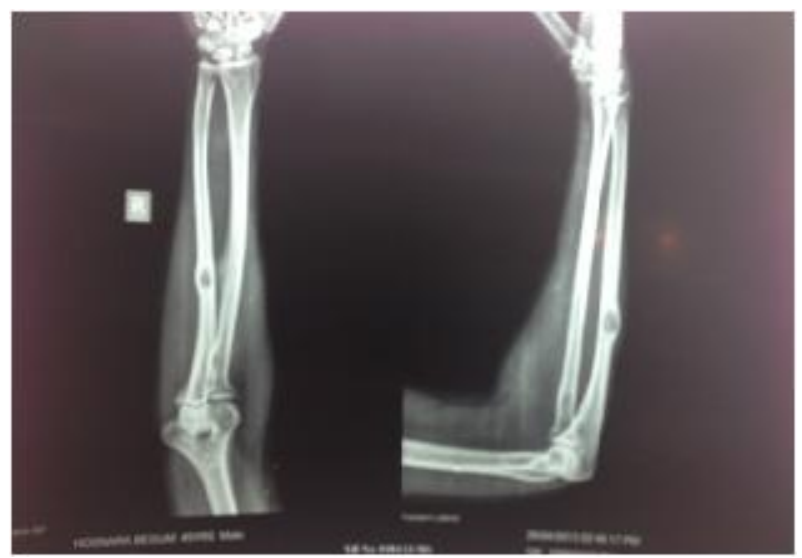

Fig 1: Osteolytic expansile lesion in the mid shaft of ulna with sclerotic margins. 


\section{CASE REPORT}

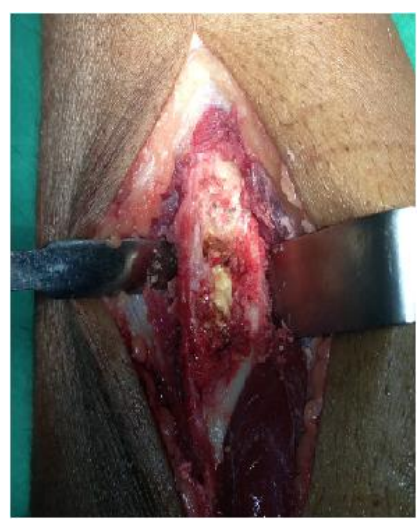

Fig 2: Yellowish soft material found filled within the cavity on opening the cortical window.

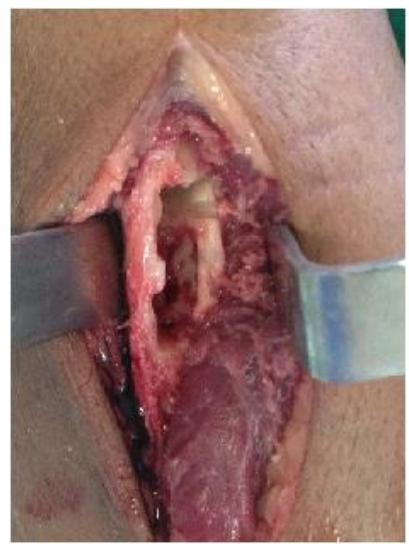

Fig 3: Sieve like perforations present in the cavity of the lesion.

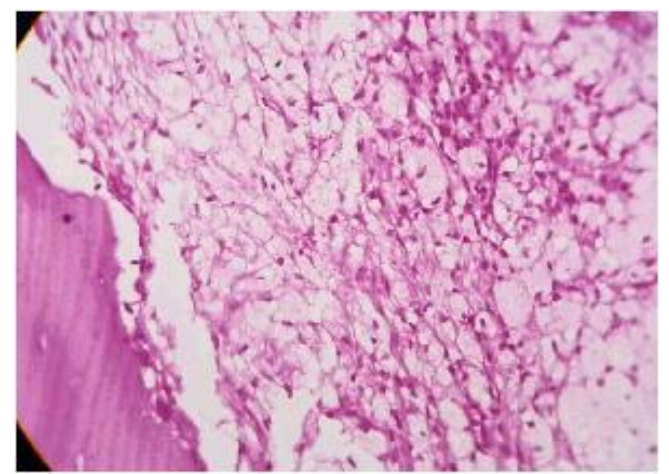

Fig 4: Sheets of lipid laden foamy macrophages with variable background of cells and fibrosis interspersed into the trabeculae. 


\section{CASE REPORT}

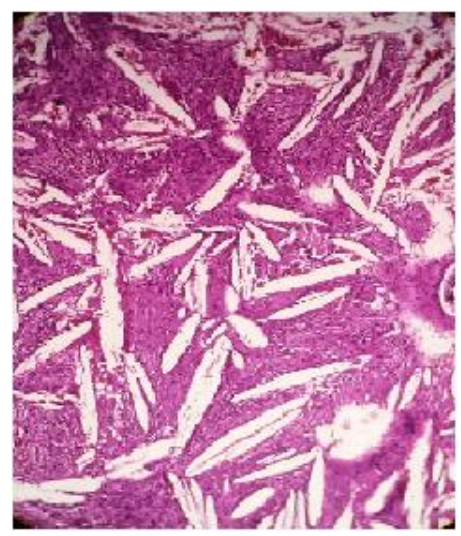

Fig 5: Areas of cholesterol clefts with giant cells around them.

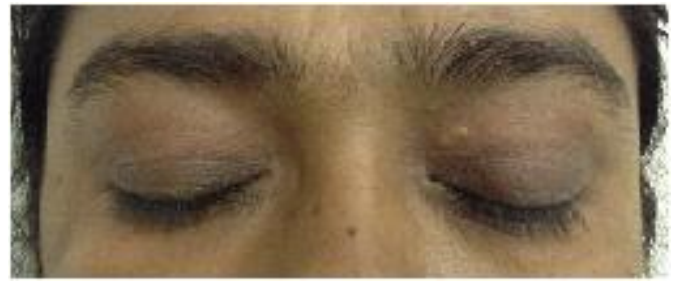

Fig. 6

\section{AUTHORS:}

1. Vishwanath Yaligod

2. Siddarth Mahesh

3. Girish H Rudrappa

4. Lokesh Choudhary

\section{PARTICULARS OF CONTRIBUTORS:}

1. Associate Professor, Department of Orthopaedics, Sapthagiri Institute of Medical Education \& Research Center, Bangalore.

2. Assistant Professor, Department of Orthopaedics, Sapthagiri Institute of Medical Education \& Research Center, Bangalore.

3. Assistant Professor, Department of Orthopaedics, Sapthagiri Institute of Medical Education \& Research Center, Bangalore.
4. Assistant Professor, Department of Orthopaedics, Sapthagiri Institute of Medical Education \& Research Center, Bangalore.

\section{NAME ADRRESS EMAIL ID OF THE CORRESPONDING AUTHOR:}

Dr. Girish H Rudrappa,

\# 506, 12 ${ }^{\text {th }}$ A Main Road, Sector - A,

Yelahanka New Town,

Bangalore - 560064.

Email - girirudra@yahoo.co.in

Date of Submission: 21/08/2013.

Date of Peer Review: 22/08/2013.

Date of Acceptance: 26/08/2013.

Date of Publishing: 27/08/2013 